(RESEARCH ARTICLE)

\title{
Advanced spinal movements (ASM) as manipulative treatment in back pain and promotion of spinal column
}

\author{
Manjunatha NS * \\ Professor and H.O.D, Department of Swasthavritta Kunwar Shekhar Vijendra Ayurveda Medical College \& Research \\ Centre Shobhit University, Gangoh, Sharanpura 247341 UP.
}

Publication history: Received on 16 December 2020; revised on 23 December 2020; accepted on 25 December 2020

Article DOI: https://doi.org/10.30574/wjarr.2020.8.3.0494

\begin{abstract}
The human back is composed of a complex structure of muscles, ligaments, tendons, disks, and bones, which work together to support the body and enable us to move around. The segments of the spine are cushioned with cartilagelike pads called disks. Problems with any of these components can lead to back pain. In some cases of back pain, its cause remains unclear. Low back problems affect the spines flexibility, stability, and strength, which can cause pain, discomfort and stiffness. Approximately $80 \%$ of individuals will experience an episode of lower back pain at some time during their life. Lower back pain is the fifth leading reason for patients visiting a doctor and the leading cause of work related disability. However, the underlying cause is usually not serious and may not even be identified by the doctor. Lower back pain is most common in patients between the ages of 20 and 40 years, but can be more severe and disabling in elderly patients. The ASM technique was implemented in private clinic with aims to increases the strength, stability \& flexibility of spine \& prevent the different kinds of back problems. As the pain was relieved almost and the patients will be encouraged to practice the ASM technique regularly, even after the pain has gone, to prevent back pain/problems recurrence and promotion of spinal column.
\end{abstract}

Keywords: Back pain; Kati shoola; Spinal movements; Kati graha; Low back pain

\section{Introduction}

According to Ayurveda Kati Shoola is a disease, it is mainly caused by vitiation of Vata Dosha. Some ancient texts also describe Kati Shoola as a symptom of some disorders such as Kati Graha, Trika Graha, Prushta Graha, Kati Vayu, Trika Shoola, Prushta Shoola, Vataja Shoola, Trika Vedana, and Grudrasi Vata $[\underline{1}, \underline{2}, \underline{3}]$.

Back pain is a common reason for absence from work and for seeking medical treatment. It can be uncomfortable and debilitating. It can result from injury, activity and some medical conditions.

Back pain can affect people of any age, for different reasons. As people get older, the chance of developing lower back pain increases, due to factors such as previous occupation and degenerative disk disease.

Lower back pain may be linked to the bony lumbar spine, discs between the vertebrae, ligaments around the spine and discs, spinal cord and nerves, lower back muscles, abdominal and pelvic internal organs, and the skin around the lumbar area.

Pain in the upper back may be due to disorders of the aorta, tumors in the chest, and spine inflammation.

\footnotetext{
* Corresponding author: Dr. Manjunatha N.S; Mob: 9886728745,E-mail: drmanjunathans@gmail.com

Professor \& HD,Dept. of Swasthavritta Kunwar Shekhar Vijendra Ayurveda Medical College \& Research Centre Shobhit University, Gangoh, Sharanpura, UP. 
The back forms the axis (central line) of the human body and consists of the vertebral column, spinal cord, supporting muscles, and associated tissues (skin, connective tissues, vasculature, and nerves). A hallmark of human anatomy is the concept of "segmentation," and the back is a prime example. Segmentation and bilateral symmetry of the back will become obvious as you study the vertebral column, the distribution of the spinal nerves, the muscles of the back, and its vascular supply. Functionally, the back is involved in three primary tasks, as follows:

- Support - The vertebral column forms the axis of the body and is critical for upright posture (standing or sitting), as a support for the head, as an attachment point and brace for movements of the upper limbs, and as a support for transferring the weight of the trunk to the lower limbs.

- Protection - The vertebral column protects the spinal cord and proximal portions of the spinal nerves before they distribute throughout the body.

- Movements - Muscles of the back function in movements of the head and upper limbs and in support and movements of the vertebral column.

\subsection{Surface Anatomy}

- Vertebrae prominence: the spinous process of the C7 vertebra, usually the most prominent process in the midline at the posterior base of the neck.

- Scapula: part of the pectoral girdle that supports the upper limb; note its spine, inferior angle, and medial border.

- Iliac crests: felt best when you place your hands "on your hips." An imaginary horizontal line connecting the iliac crests passes through the spinous process of the vertebra L4 and the intervertebral disc of L4-L5, providing a useful landmark for lumbar puncture or epidural block.

- Posterior superior iliac spines: an imaginary horizontal line connecting these two points passes through the spinous process of S2 (second sacral segment).

\subsection{Vertebral Column}

The vertebral column (spine) forms the central axis of the human body, highlighting the segmental nature of all vertebrates, and usually is composed of 33 vertebrae distributed as follows

- $\quad$ Cervical: seven total; first two called the atlas (C1) and axis (C2).

- Thoracic: 12 total; each articulates with a pair of ribs.

- Lumbar: five total; large vertebrae for support of the body's weight.

- Sacral: five fused vertebrae for stability in the transfer of weight from the trunk to the lower limbs.

- Coccyx: four total; Co1 often is not fused, but Co2-Co4 are fused (a remnant of embryonic tail).

- The actual number of vertebrae can vary, especially the number of coccygeal vertebrae.

The atlanto-occipital joint permits flexion and extension (e.g., nodding in acknowledgment), and the atlanto-axial joint allows side-to-side movements (rotation; e.g., indicating "no"). This is accomplished by a uniaxial synovial joint between the dens of the axis and its articulation with the anterior arch of the atlas. The dens functions as a pivot that permits the atlas and attached occipital bone of the skull to rotate on the axis. Alar ligaments limit this side-to-side movement so that rotation of the atlanto-axial joint occurs with the skull and atlas rotating as a single unit on the axis

\subsection{Movements of the spine are a function of the following features}

- $\quad$ Size and compressibility of the intervertebral discs

- Tightness of the joint capsules

- Orientation of the articular facets (zygapophysial joints)

- Muscle and ligament function

- Articulations with the thoracic cage

- $\quad$ Limitations imposed by the adjacent tissues and increasing age

\subsection{Aims \& objectives}

- To see the efficacy of the treatment/ASM on back pain

- To increases the strength, stability \& flexibility of spine

- Promotion of health of spinal column 


\section{Material and methods}

A study was conducted at my private clinic "Om Ayurveda \& Yoga Health Centre", Davanagere, Karnataka, India. Total 60 cases with the age between 20-50 years were selected, out of which 38 are females, and 22 are males were visited to clinic with the complaints of back pain.

ASM sessions with a therapeutic focus were held daily for $60 \mathrm{~min}$ in morning sessions directed by me. Each session began with deep breathing exercises and relaxation techniques progressing to poses designed to begin with stretching and move into strengthening [Table 1]. The session ended with meditative relaxation. The first week slow \& mild session emphasized restorative poses and the second week session was more movement based. The predesigned ASM program progressed from simple to more challenging movements over the 4-week course. Modification for restricted movement or painful positions was provided as needed. Safety issues were monitored.

\subsection{Inclusion criteria: back pain due to}

Low back pain, the most common musculoskeletal disorder, can have various causes. Physical examination, although not always revealing a definite cause, may provide clues to the level of spinal nerve involvement and relative sensitivity to pain. The following causes are identified most often:

- strained muscles or ligaments

- a muscle spasm

- muscle tension

- Adopting a much hunched sitting position when using computers can result in increased back and shoulder problems over time.

- Twisting

- over-stretching

- bending awkwardly or for long periods

- pushing, pulling, lifting, or carrying something

- standing or sitting for long periods

- straining the neck forward, such as when driving or using a computer

- long driving sessions without a break, even when not hunched

- sleeping on a mattress that does not support the body and keep the spine straight

\subsection{Exclusion criteria}

- Pregnancy

- Intervertebral disc rupture and herniation

- Fracture of vertebral bone

- Degenerative changes in vertebral facet joints

- Sacro-iliac joint and ligament involvement

- Metabolic bone disease

- Psychosocial factors

- Abdominal aneurysm

- Metastatic cancer

- Myo-fascial disorders

\subsection{Assessment criteria}

- X-ray

- MRI/CT scan

- ESR

- $\mathrm{CBC}$

\subsection{Advanced spinal Movements}

- Stretch-fully (as patients comfort) clockwise \& anti clockwise rotation of thoracic, lumbar and sacral spine in a wave like with slow motion for 10 rounds each.

- Stretch-fully movement of whole spine curvature from lower to upper \& upper to lower in a wave like for 10 rounds each.

- Head \& neck movements: - side ward bending, forward \& backward bending \& rotation clockwise \& anti clockwise. 
- Thoracic \& lumbar: - side ward bending, forward \& backward bending \& fully stretch (as patient comfort) rotation clockwise \& anti clockwise.

- Twisting

Above said A \& B are special movements of spine (Fig. 1) \& other essential movements (C, D \& E) of the spine are flexion, extension, lateral flexion (lateral bending) and rotation (Fig. $2 \& 3$ ) are starts with 2-3 rounds with slow motion in beginning and gradually increased up to 10 round counts and the speeds up to medium level. Continue the procedure for 30 days.

The greatest freedom of movement occurs in the cervical and lumbar spine, with the neck having the greatest range of motion. Flexion is greatest in the cervical region, and extension is greatest in the lumbar region. The thoracic region is relatively stable, as is the sacrum.

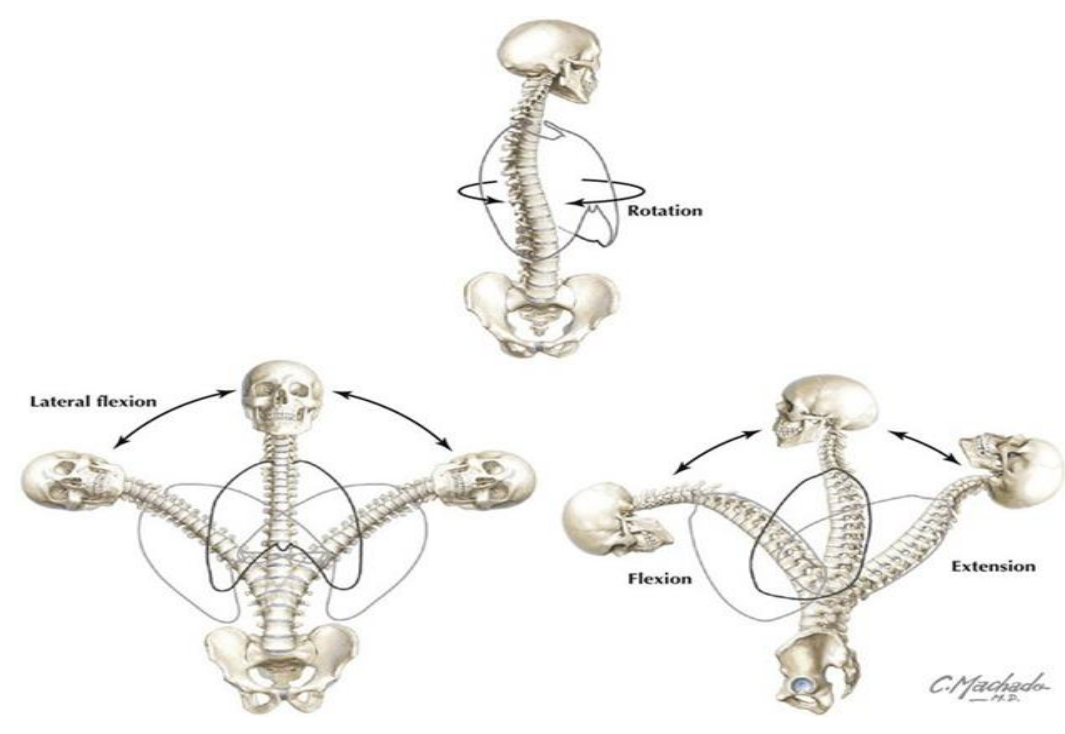

Figure 1 Special spinal movements
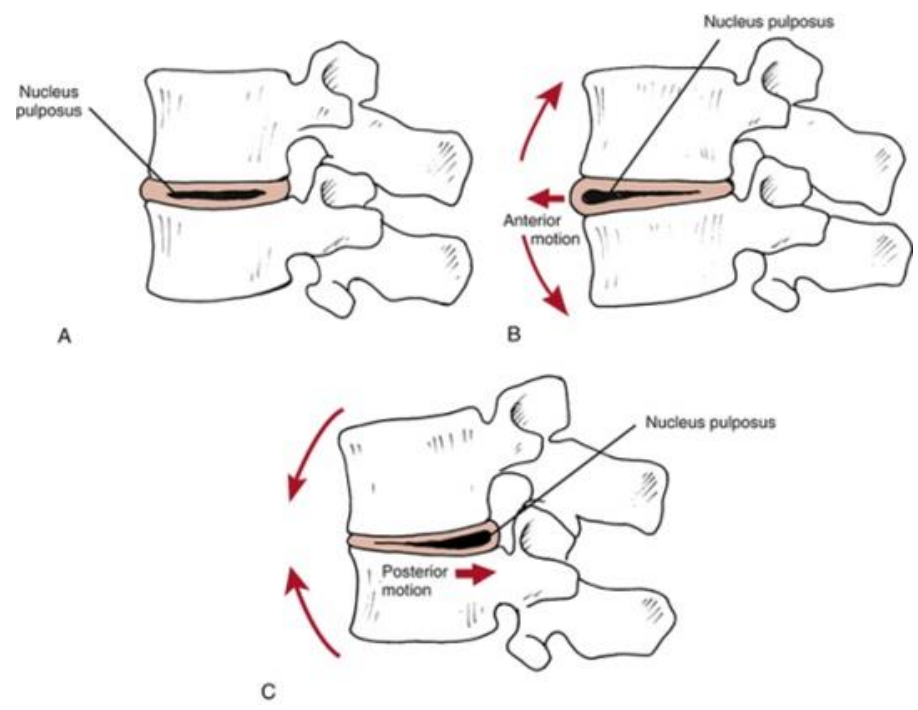

Figure 2 Effects of spinal movements on the intervertebral disc 

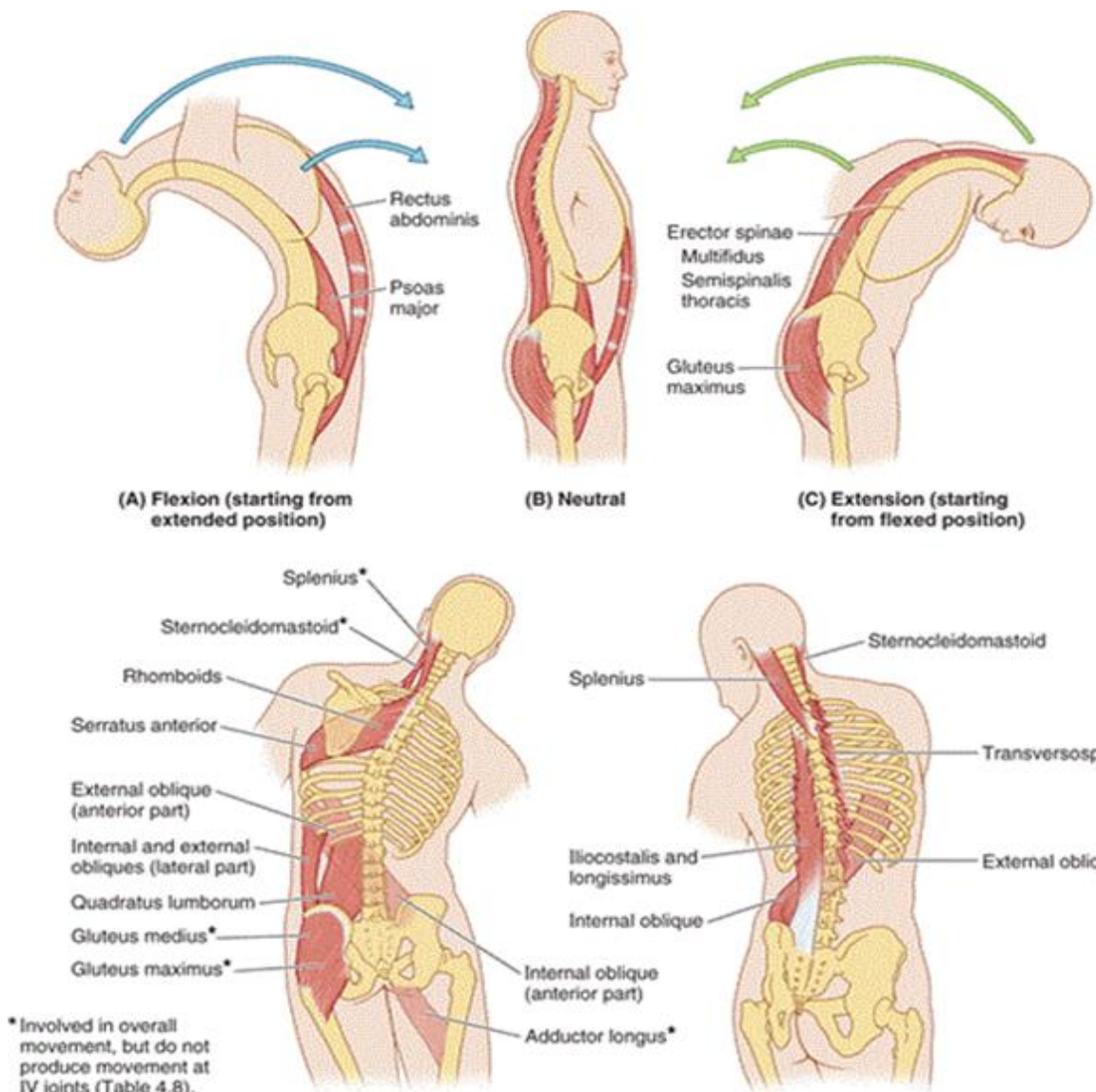
(C) Extension (starting
from flexed position)

Figure 3 Effects of spinal movements on the muscles

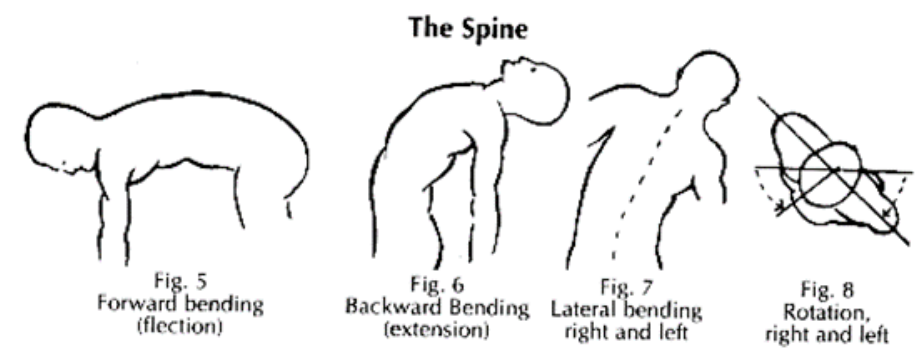

Figure 4 Essential spine movements

\section{Results and discussion}

The mean age of all subjects was 35 years, most were married. The mean body mass index $(\mathrm{kg} / \mathrm{m} 2)$ was 25.5 , which is considered overweight. The average duration of the pain was greater than 3 months. The subjects identified the most common reasons for low-back pain as long standing working women, long time sitting without movements, bending or lifting injuries, work-related mild strains and unknown. 
Table 1 grading/scoring of pain while movements

\begin{tabular}{|l|l|l|}
\hline Sl no & Intensity of pain & Grade \\
\hline 1 & No pain & 00 \\
\hline 2 & Occasional pain & 01 \\
\hline 3 & Intermittent pain & 02 \\
\hline 4 & Frequent pain & 03 \\
\hline 5 & Continuous pain & 04 \\
\hline
\end{tabular}

Table 2 grading/scoring of pain while flexion

\begin{tabular}{|l|l|l|l|}
\hline S.no & Intensity of Pain on anterior flexion & Intensity of Pain on posterior flexion & Grade \\
\hline 1 & No pain up to full flexion & No pain up to full flexion & 00 \\
\hline 2 & Mild pain @ full flexion & Mild pain @ full flexion & 01 \\
\hline 3 & Moderate pain @ full flexion & Moderate pain @ full flexion & 02 \\
\hline 4 & Severe pain while flexion & Severe pain while flexion & 03 \\
\hline 5 & Cannot flex & Cannot flex & 04 \\
\hline
\end{tabular}

Table 3 Evaluation of clinical symptoms

\begin{tabular}{|l|l|l|l|l|l|}
\hline Sr No & Symptoms & $\begin{array}{l}\text { Before treatment } \\
\text { grade }\end{array}$ & $\begin{array}{l}\text { After treatment } \\
\text { grade }\end{array}$ & t-value & p-value \\
\hline 1 & $\begin{array}{l}30 \text { patients - Pain in low } \\
\text { back (kati shoola) }\end{array}$ & 03 & 01 & -215.072 & $<0.00001$ \\
\hline 2 & $\begin{array}{l}20 \text { patients - Pain in back } \\
\text { (prushta shoola) }\end{array}$ & 02 & 00 & -118.654 & $<0.00001$ \\
\hline 3 & $\begin{array}{l}10 \text { patients - Neck pain } \\
\text { (greeva shoola) }\end{array}$ & 01 & 00 & -82.819 & $<0.00001$ \\
\hline 4 & $\begin{array}{l}\text { Degree of anterior flexion } \\
\text { Degree of posterior flexion }\end{array}$ & 02 & 00 & -643.614 & $<0.00001$ \\
\hline 5 & 02 & 00 & -643.614 & $<0.00001$ \\
\hline
\end{tabular}

We have observed after four weeks of ASM as per our regimen, the patients were relieved completely in 85-90\% significantly in 15\%, moderately in $10 \%$ and slightly in $6 \%$. Patients reported no relief in $2 \%$ and pain. The result is very significant at $\mathrm{p}<0.01$.

ASM helps to relax the back muscles, releases stiffness at the back and strengthen the back muscles and it improve the movements \& posture. Care must be taken that movements/exercises do not make back pain worse.

The patient will be encouraged to practice the techniques regularly, even after the pain has gone, to prevent back pain recurrence and promotion of spinal column. 


\section{Conclusion}

Advanced spinal movements are very good for individuals with back pain, because it does not have any risk of future back injuries or work absence. Substantial use ASM exercise as a therapeutic tool to improve impairments in spinal flexibility and strength. This study has improvements in pain ratings after ASM, and we sure that ASM can lessen the behavioral, cognitive, affect and disability aspects of back pain syndromes.

\section{Compliance with ethical standards}

\section{Acknowledgments}

Acknowledgments must be inserted here.

I would like to express my thanks of gratitude to our participants (patients) to do this wonderful study on the topic "Advanced spinal movements (ASM) as manipulative treatment in back pain and promotion of spinal column" which also helped me in doing a lot of Research.

\section{Statement of informed consent}

I Dr. Manjunatha NS author of this article, herewith I am giving the statement of conformed consent of all individual participants of this study.

\section{References}

[1] Sharma PV, editor. Charaka Samhita, Chikitsa Sthana, Vata Vyadhi Chikithsa Adhyaya, 28/28. 2nd ed. Varanasi: Chaukhamba Sanskrit Sansthan. 1990;

[2] Murthy KR, editor. Susruta Samhita, Nidanasthana, Vata Vyadhi Nidana 1/20. Varanasi, India: Chaukhambha Orientalia. 2000;

[3] Murthy KR, editor. Madhava Nidana, Vatavyadhi Nidana 22/14, 57. Varanasi, India: Chaukhambha Orientalia. 1986; 